\title{
THE POWER OF POLITICAL SUBLIMINAL MESSAGES IN KASHMIR BASED MOVIES HAMID AND HAIDER
}

\author{
Sundas Nadeem \\ Riphah Institute of Media Sciences \\ Islamabad - Pakistan \\ sundas29nadeem@gmail.com \\ Dr.Noman Ansari \\ Assistant Professor \\ Riphah International University \\ Islamabad - Pakistan \\ noman.ahmed@riphah.edu.pk
}

\begin{abstract}
Subliminal messages are those concealed and hidden messages which are not effectively noticeable and can control an individual's mind without them being aware. Films can affect the overall audience's mind and make roads for their thinking of the issue. They can change the perception of people about explicit and unfortunate occasions and subjects. This research explored if there are any subliminal messages present in the movie Hamid along with the movie Haider and does these movies aim to target the ongoing freedom movement in Kashmir. Moreover, the basic objective is to understand that how the Indian movies portrayed Kashmiri Muslims. The number of literature writing associated with subliminal messages in movies advertisement and other mediums is highlighted in this research. This study aims to analyze the visual of the film Hamid and Haider and intensely identify any subliminal messages, in the form of visuals and linked its relation with the freedom movement in Kashmir. The proposed method to lead the research is multimodal discourse analysis. To carry out these analyses Visual Social Semiotic Theory by Jewitt and Oyama. Results showed that there are subliminal messages which are targeting and manipulating the audience to show
\end{abstract}




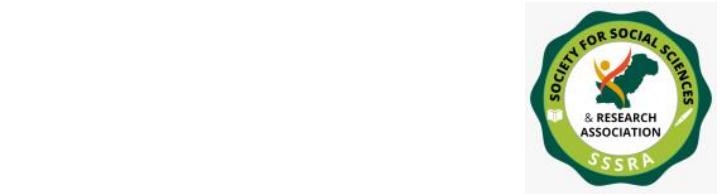

Pak. Journal of Int'L Affairs, Vol 4, Issue 3 (2021)

The Power of Political Subliminal ...

different perspectives of freedom movement and Indian brutality or violence. Hamid and Haider reveal the pith of the speculation which expresses that Indian media and Government incorporate Subliminal messages which project a hidden boost and targeting freedom movement mean jihad is a call to slaughter, to torment, to rebuff which the Quran legitimize.

Keyword: Subliminal message, bollywood movies, kashmir, freedom movement, haider, hamid.

\section{Introduction}

This research will explore is there any political subliminal messages present in the movie Hamid along with the movie Haider and does these movies aim to target the ongoing freedom movement in Kashmir. Moreover, the basic objective is to understand that how the Indian movies portrayed Kashmiri Muslims. The movies are available on Netflix to watch by everyone and a new strategy to show the entire world what is happening in Kashmir. Before going into detail it is necessary to understand what subliminal (Hidden) messages are?

Promoting, music, climates, Hidden messages and movies can affect our enthusiastic life, and we cannot control it since we are not in any case aware of it (Ramadan T. , 2010).

Subliminal messages are concealed messages that are installed in another medium to act purchaser's intuitive personality. Researchers think there are 3 forms of subliminal (Hidden) messages visual, auditory, and combination of hidden messages (Atrees, 2015).

Hidden messages are being used for years in political camping, comics, movies, posters, etc. The controversy started when James Vicary's study said "Drink coke, eat popcorn" has increased the rate of the movie at a refreshment box (Nika, 2013). In the cartoon Johnny Bravo, there was a poster of a plane crashed in a building title coming soon indicating the 9/11 incident (Amre, 2017), Even the Simpson cartoon has many hidden messages regarding Donald trump's candidacy (Marchman, 2016).

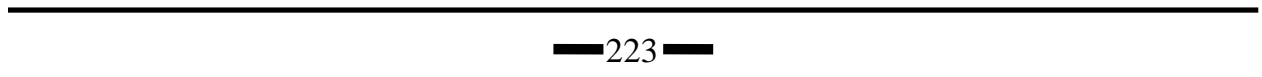




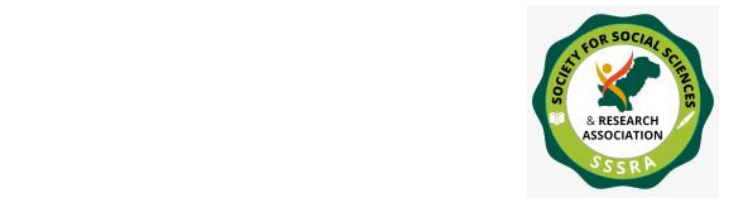

The Power of Political Subliminal ...

India's main aim is to target the Azadi movement in Kashmir and Bollywood is an effective way to deliver their point now the world has to change its perspective now they use a soft power approach to target the other by putting a subliminal message to deliver their message and target. In mission Kashmir they frame Kashmir. Spenser in his article wrote the obsession of Bollywood with the Kashmir issue. In the movie Mission Kashmir in which subliminal message was in the narrative of a film where male protagonist Altaaf want revenge of his family his desire for Azadi his anger with Inayat khan for killing his family but when the anger defuses the movie depicts the happiness of people of Kashmir and Indian together. The subliminal message here is the movie target the freedom fighters that your anger with India will not give you peace and happiness. This depicts the perspective of Bollywood how they perceive this freedom movement and how they portrayed to the world how they frame the Kashmiri movement by targeting them through the subliminal way this framing is a tactical tool to target. (Spencer, 2019)

Initially Cinema is considered as an entertainment tool. Yet, propagandists who have learnt the common interest of the audience in film and the ideology any individuals wanted to convey in broader number of audience take movies as a tool and use it for their own interest. Numerous nations have made their film and successfully utilized the film to scatter their framework and philosophy to the audience. Ideological political codes in films can be seen in some Hollywood movies, whereas in some movies it's in the hidden form. Audience are deeply affected by films and cinema. When the audience watch the movie they watch it very attentively and film is directly effecting their subconscious mind. Audience is not aware that these messages are effecting their mind without them being aware. Good or bad is represented in some movies. /in some cases audience doesn't like the message but in movie it represent in such a way that they like it in movie and sometime it changes their opinion. Unwittingly he adopts that message. For example, in many movies America is a strong nation in politics and cultural has been presented, justified, appreciated, and admired. This was especially seen in films that were shot in organization with the Pentagon and the United States Department of Foreign Affairs. (Çelikiz).

The visual substance has for quite some time been a fundamental piece of communication whether political, social, International, or business-related. Well-known online networking stages, for example, Facebook and Twitter have filled in as significant 


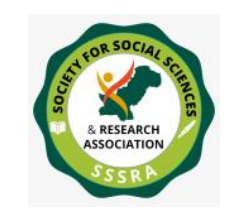

The Power of Political Subliminal ...

scenes for political on-screen characters in the struggle to share pictures as a piece of their propaganda informing. Seo's (2016) analysis of Twitter pictures posted by the Israel Defense Forces and Hamas' Alquassam Brigades during the November 2012 Gaza struggle indicated that the two sides utilized different topics and casings to stress the losses of their side and to depict the opposite side as the attacker. Every picture was broke down for Theme, Frame, Human Characters, and Production Format Theme: categories: Resistance, threats from the enemy, casualties of own civilians, casualties of own soldiers, destruction, unity, and humanity.

India appears to succeed as a soft power by defaulting with her self-governing tradition, Mahatma Gandhi with his perception of self-restraint and peaceful fight arbitration as national champion, and Bollywood as a quasi-global vision fabric. The high monetary development rates since the progression in 1991 have expanded India's global attractiveness. India utilizes its soft power abilities mostly for image building rather than as a tool to utilize influence. India can then be capable as a cautious soft power that places sturdier importance on its abilities rather than the competencies. In comparison to America (US), the European (EU), and China, Indian overseas policy creators do not see their political model as a fascination for others. It is observed as an asset that is endorsed to upsurge India's attraction for international investors. The ironic condition was the Kargil battle when it won the world regard and also increased admiration for not overpass the borders. In Afghanistan they effectively use soft power by building infrastructure and providing scholarships to Afghans, providing them entertainment that can easily manipulate and change the perception of Indians in front of the world and Afghans. This is a subliminal message to the other countries (Wagner, 2010).

The Bollywood industry is not behind it they use political messages as well. Indian Foreign Ministry has a strong relation with Bollywood. The Indian government is actively exploiting Bollywood's potential as a tool to achieve foreign policy goals. In the recent decade, Bollywood has produced movies revolving around political themes and advancing the Indian government's political agenda in the region. Especially after the Kargil War between India and Pakistan in 1999 and ensuing tension in the region due to terrorist activities in India, Bollywood had produced movies that reflected the nature of relationships between the South Asian neighbors. These movies had strong patriotic and jingoistic undertones that aligned with the government's foreign policy. However, when a 


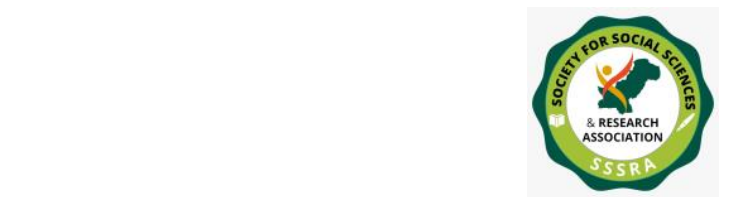

The Power of Political Subliminal ...

process of détente had caught momentum in the region after 2003, a few movies were released that aimed at promoting harmony and friendship between India and Pakistan. (Rasul, 2015).

\subsection{Research question}

RQ1: What Visual subliminal messages are present in Hamid and Haider's movie?

RQ2: Do these visual subliminal messages targetting on freedom movement and the Muslims in Kashmir?

\section{LITERATURE REVIEW}

Literature writing associate with subliminal messages in movies highlighted in the early researches. Films can affect the overall public and make roads for their thinking of the issue. They can change the perception of people about explicit and unfortunate occasion.

Subliminal messages have been, around for as long as we are being exposed to films. There are two forms of subliminal messages, one that is hidden and the other are those that are either narrated through the storyline or the appearance of the character and their narrations. (Takahashi, 2008).

Subliminal messages grab the attention of the researchers when the scholar James Vicary did an experiment by projecting the subliminal Ad "Drink coke and Eat popcorn" in a film picnic. It was Brand promotion and to introduce the new trend in the theater of promoting beverages and the other aim was to investigate the outcome of the subliminal message. The message provoked the audience to get the popcorn and coke which expanded $57.8 \%$ popcorn sale, \& $18.1 \%$ in a coke sale separately in a New-Jersey theater. (Packard, 1957). After much publicity of Coca-Cola research, hidden agendas grabbed the eye of the commercial world. Government starts financing on the topic of subliminal perception. (Russell, 1991). Researcher Wilson Bran identified subliminal messages in ads. He said sellers intend to project subliminal messages to grab the target audience and 


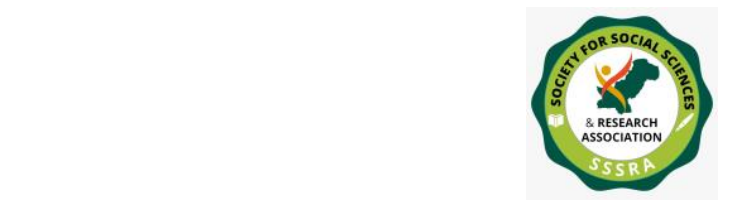

The Power of Political Subliminal ...

they use a specific technique to grab them for instance, naked body, underneath a skirt or sexual visuals to create curiosity and grab the young college student's attention to purchase the products and amenities (Vokey, 1985).

Since the 1950's Subliminal Marketing has been around with Coca-Cola being the first to present it. Many associations acknowledged the new strategy to grab the audience's attention and promoting their products. The benefit of such endorsing is that clients accidentally get their attention dragged into the product which further pushes them to get the product. For instance, in the epic film The Lord of the Rings, "The One Ring that Rules Them All" had the words Coca-Cola engraved mean Coca-Cola is the key to rule showing a subliminal message (Malika Singh, 2015).

Homeland is an American series that had many subliminal messages by negatively depicting Islam and Muslims and the audience has no idea that they were targeting and manipulating their views regarding Islam and Muslims without them being aware even they justify all actions and activities of Americans and Israelis on Arab. The embedded and projected American contempt towards Islam. The entire series was embedded with anti-Islam sentiments which create Islam phobia. For Instance, they show Quran legitimizes slaughtering and radicalism focusing on Jihad executing and decapitating and everything is rooted in their book Quran. Portraying the Pakistan backward country which stops women to get an education, there was an audio's subliminal message where Pakistani women were stating how their kin and government don't give them the right of casting a vote and halting them for their fundamental right. Another audio subliminal message which anticipated was Hilary Clinton's speech in which she was linking the Muslim with a snake. Portraying a German and American woman are manipulated by Muslims to join ISI for the terrorist mission and they felt guilty after killing innocent people only the name of Islam and Allah. The entire homeland series questioned Islam and their education by depicting Muslim negative and American as legends (Deba, 2016).

In one of the research, the Japanese students researched Hollywood movies how they endorse famous brands and how they are promoting and placing tactfully in almost all their movies without being aware of viewers. Coke and other big brands openly endorse their products in a movie for instance. Breakfast, in Tiffany endorsing brand the 


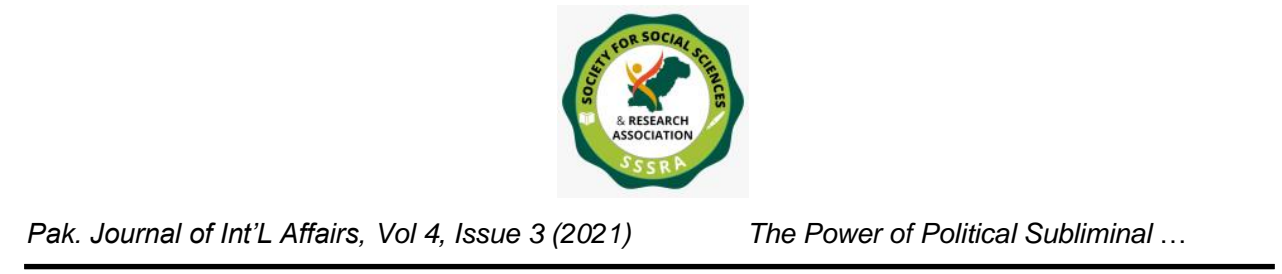

famous diamond brand Tiffany in the title of the movie. In the movie, I am Sam endorsed the Starbucks new marketing message, Sam who is a mentally ill person working in Starbucks It was a subliminal message which was hidden in the narrative of the movie. The product would be more effective if these subliminal messages give them knowledge of the product in an effective way and a movie is an effective way of endorsing and conveying the message. (Anzai, 2003).

Yunru Chen (2015) investigated six movie posters that have some hidden meaning behind them. All those posters use some illustrative semiotics visuals associated with text and design cooperate in acknowledging the illustrative significance of film posters. For instance, the banner, THE FLOWER OF WAR has some conceptual hidden meaning where hues Red depicted the merciless and a passionate story, the flower is defined as the vehicle, and tenor portray as a woman. The Poster portrayed a flower as a butterfly representing a feeling romantic tale of wartime. In the same way one of the posters THE QUEEN in which sovereign Elizabeth's figure portrays the entire story is about her and princess Diana's picture in the background and black shadow color characterize the story is related with her passing away. Projecting Dianna's picture in the background of the poster has hidden meaning first is to grab the audience attention that story is related to her relationship with the Queen and Diana picture with grey color indicate maybe it is related to her death. In the same way, American beauty poster in which rose is placed on the flat young belly which symbolizes many hidden meaning and viewers focus on the subject of the movie. Moviemakers purposely create these posters with some hidden symbols or visuals to create curiosity and chaos among the audience.

Tom Cruise and Nicole Kidman's movie "Eyes Wide Shut "has predominated subliminal messages. Although the film is about husband and wife dealing with their problems that is just a cover-up in actual the entire movie is tons of secrete hidden symbolism of elite society in which the rituals and symbolism indicating its relation to the Illuminati. The building of Mentmore Towers where all most all the scenes and rituals were performed and describing the elite society secretes own by the Rothschild one of the world strongest and wealthiest Jewish family even Ziegler character is portrayed as similar to Rothschild. A Triangle pyramid shape is shown on the blinds depicting the power and class system. The lightning star on the wall depicts the symbol of Ishtar which means goddess who gave birth to the world love war sexuality almost everything. There 


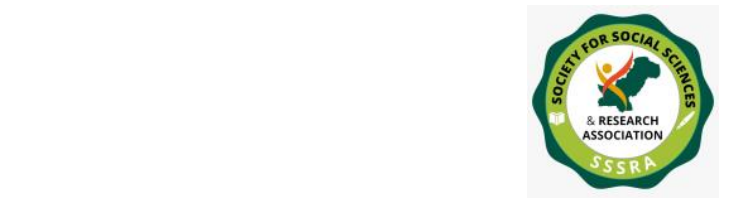

Pak. Journal of Int'L Affairs, Vol 4, Issue 3 (2021)

The Power of Political Subliminal ...

are many other subliminal messages in the movie which depict that the movie was in actual wants to tell the secretive of elite society and their stand. (Florea, 2016).

Walt Disney and Looney Tunes were among those that effectively helped the U.S. war exertion through their kid's shows which gave preparation and directions to viewers just as a political editorial on the occasions. One of the most famous, Der Fuehrer's Face (1942) was a cartoon for soothing the hostility against Hitler by making him a to some degree amusing figure while exhibiting the opportunity America advertised. Education for Death: The Making of the Nazi by Gregor Ziemer, given a smash hit book, withdraws from the Disney standard by indicating how Nazis influence blameless young boys and indoctrinate them into accepting gathering philosophy. The New Spirit (1942) was one of the principal films the legislature contracted with Walt Disney to make. The Treasury Department required a film to address Americans and persuade them to pay their annual assessment during WW. (Cunningham, 2014).

It is an agenda which government put political message. Movies become an easy way to shape up the perception. They use, subjects or issues to grab the attention of what people should think about then how to think about it, sometimes bluntly openly and sometime through subliminal messages. When bhagat singh fought against British rule, he was called freedom fighter or a fight for freedom and portrayed a very positive character in Bollywood movies similarly, when Muslim of Kashmir are fighting for the freedom are labelled as terrorist and depicted as negative. (Birgit Meyer, 2005)

Movies have become a complete channel to transmit political messages to the public. The difference is that, in the case of manipulation, the transmitted ideas are hidden and not presented to the public in an obvious manner; attention is directed to another part and the ideas are brought in through the "the back door", while the conscious mind focuses on other things, the sub-conscious is unprotected and reflexively absorbs the message. "Representation of political ideology through Bollywood movies. Uri: The Surgical Strike signified that there is representation of political ideology of ruling party BJP in the movie. The movie and characters were inspired with the real political figures and incidents. The study also discussed the representation of the PM Modi ideology and role in the surgical strike on the basis of cinematography. (Banga) 


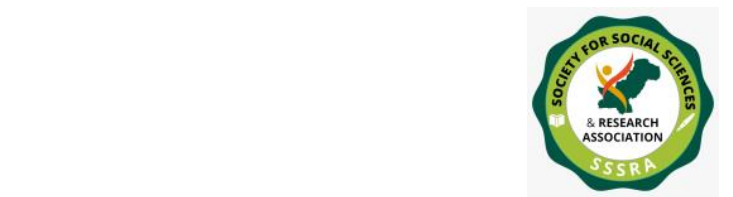

The Power of Political Subliminal ...

American movies are the most engendered imperialistic films and there are different hidden messages in them. Iron man series is one of those films which has many proliferated scenes which has some subliminal meaning. There is a deleted scene where tony stark was seized by Afghani snare when he woke up they were talking in Urdu now the point here is they were depicted as a terrorist in Afghanistan however the language they were speaking was Urdu. The scene was deleted however the question that rises here is why they have to shoot it and deleted then leaked it. In Iron man 3 the character of Mandarin is depicted as Osama Bin laden by giving him the eastern look with long beard and his views on Americans and accepting the assault on Chinese theater, in particular, his discussion on oil enterprise since middle eastern people thought of utilizing oil as a weapon against crusaders, obviously, In Iron man 3, the character of Mandarin depicted as an Osama Bin laden by giving him the middle eastern look with long beard and his view on Americans and accepting the attack on Chinese theater, most importantly his conversation in oil corporation because middle eastern people thought of using oil as a weapon against crusaders, clearly portraying him Islamist terrorist. Not just had the film depicted a Mandarin character as manikin who is working for Aldrich, a scientist who is doing all the stuff out of envy and business. An iron man mentions that terrorism is exaggerated by some businessperson and government officials for their benefit since terrorism, war is a major business and the American businessman and politician manipulate it for their interest. The other important message in the film was that expanding the military on such territories isn't an answer to the issue and a foreign strategy likewise has its contribution in exaggerating terrorism. (Cole, 2018).

In the film Black and white they target the jihad concept through the subliminal way where they depict a Hindu educator recounting the quranic ayahs and in a similar time they show a scene of Afghanistan where terrorists are planning a bombing in India and reciting "By killing the disbeliever's in the way of Allah, heaven will be obtained" nowhere is a subliminal message, they target Jihad by misguiding it with brutality violence killing innocence which is against the humankind they deliberately portrayed the situation of Jihad to misguide. (Khan M. A., 2011).

From all this research done this study comes across a point that subliminal messages are not just images or sound hidden in the background, they are also those messages that are narrated through the storyline. The story always narrated an agenda or 


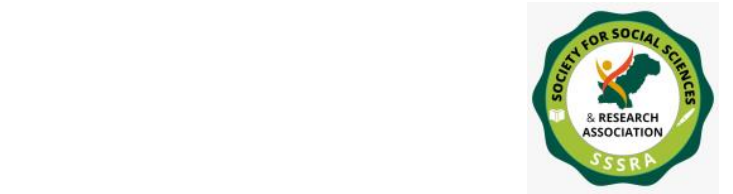

The Power of Political Subliminal ...

follows a specific ideology that is narrated throughout the movie from beginning to the end. Many movies projectPolitical subliminal messages to target something. The movie can change the perception of an audience because most of the time ordinary people watch the movies of such events and absorb the message without searching the whole truth, so movies can easily manipulate people's minds. Films comics, animated cartoons, and so on all carried messages that supported the war or change the perception for propaganda purposes. For instance, after watching the movie Pearl Harbor people (who didn't know the history and have the least interest in history) thought it was a romantic tale but it was a political movie that put the Japanese in a negative light and justify the nuclear bombing on Hiroshima and Nagasaki. Hence this study selected two Bollywood movies Haider and Hamid for not only to identify the political subliminal messages but also to examine the basic ideology of Kashmiri that has been portrayed in the storyline of Bollywood movies.

\section{METHODOLOGY}

This study aims to analyze the visual analysis of the film Hamid and Haider and intensely identify any subliminal messages, in the form of visuals and drive its relation with the freedom movement in Kashmir. The proposed method to lead the research is multimodal discourse analysis and in multimodal discourse analysis, a visual analysis will be favored. To carry out this analysis Visual Social Semiotic Theory by Jewitt and Oyama will be applied which is divided into three (3) components, Representational, Interactive and compositional meaning.

\subsection{Subliminal Messages}

Primarily, subliminal messages refer to the visual display or the auditory presentations of vague perspectives which are difficult to be assessed by a cautious mind. Subliminal messages roam within the context of a story, hence, have a deeper meaning and value to them (Ruch, 2016). In the current case, where Hamid and Haider are being critiqued as two Hollywood movies based on the situation of Kashmir, the presence of a subliminal message is undeniable. There are several subliminal messages in both the film, and they highlight, the cruelty of war, oppression caused by terrorism, mental disorder, revenge as a factor fueling the fire, brutality, and value of peace (Wehrmann, J., \& Barros, R. C., 2017). However, the main message was how the Kashmiris suffered due to 


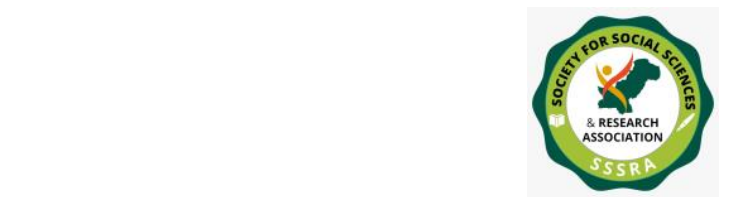

The Power of Political Subliminal ...

the disputes between the two countries and how the Indian army is provoked by militants towards hostile Kashmiris just in case of a small suspicion (Amin, 2017).

Based on how the story of Haider unfolded over time, a major subliminal message which is often ignored is that Kashmiris should forget about vengeance and should support the idea of working in collaboration with the Indian government (Khalidi, 2019).The message translated in the movie Haider is that hate, and vengeance does not lead a person to a better life, however, torn apart the already assembled lifestyle of a person. As mentioned above, cruelty, brutality, retaliation, and oppression is being faced by the Kashmiris, however, like a subliminal message translated by the movie Haider, rather than hating the Indian government, Kashmiris should cope with the uncertainties and should abide by the regulation of India (Cartelli, 2019), as vengeance cannot seek happiness.

'Hamid' though not as infamous as Haider is of significant value to discuss the topic at hand and identify the subliminal messages. Similarly, considering the environment of Kashmir as the embodiment of the story, Hamid shares a lot of traits with Haider (Mookherjee, 2016)As far as the key subliminal messages are concerned, the movie highlights resilience to be an element that can help people strive forward even after being a victim of some major tragedy. In the case of Hamid, the death of his father was finally overcome by her mother and himself once they grieved enough and once a significant time had passed (Slater, 2019)Hence, like a subliminal message from the movies, with time even the saddest of tragedies can be overcome as life and time never stops.

Linking Hamid and Haider, the two films shared a similar subliminal message concerning the fact that tragedies can be overcome, and resilience can be man's best trait as rather than approaching vengeance, moving forward carves upon the righteous path, the path which protestor has chosen provoke Indian military and government to take severe action.

\subsection{Multimodal Critical Discourse Analysis}

Multimodal discourse analysis is one of the hypotheses for examining media communication presented by Kress and Van Leeuwen (2006). Multimodality is 


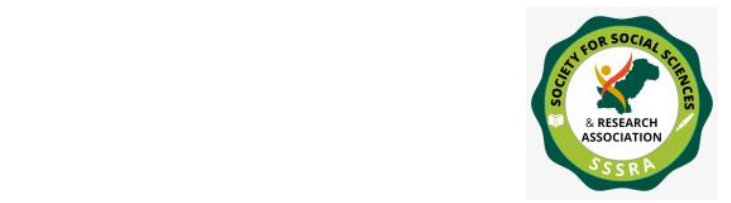

The Power of Political Subliminal ...

accustomed to examining and understanding visual pictures and the association between a verbal and visual component in media communication. Kress and Leeuwen perceive the three Meta functions as ideational, relational, and textual. It provides an organized and systematic way not only to analyze the linguistic-related research but also other semiotic methods like images symbol signs. Multiple layered approaches are needed to analyze visual communication because they covered different communication forms like TV, Movies, Magazines, etc. these are not only communicated through language but also sound, music, images, and other modes. helps you to understand the analysis of the particular mechanism with future adaptive methods it helps you to see the research from the perspective in which language and signs are studied in-depth and interpret the meaning as well... It changes its pattern from static to dynamic recently now discourse analysis talk about music images sound and action. Multi-modal discourse alludes to utilizing visual, sound, sense multi-lingual image framework to convey through multimeans and image assets, for example, character, picture, sound, and activity. This Research studied how the visual and textual and verbal elements together created the subliminal meaning by using the Multimodal discourse analysis method by Kress and van Leeuwen methodologies.

\subsection{Why Visual analysis}

In both movies, subliminal messages are either in visual images where a text is written on Road or in narrative form. Visual Social Semiotic Theory by Jewitt and Oyama will be applied they divided theory into 3 components:

3.3.1 Representational. In representational what participant is used to convey your message it can be anything person, place, or thing. The representational is further divided into two categories.

- Narrative. In which participant is conveying a message through Action, Transactive and Non-Trans active

- Conceptual. Study of the participant through sense

3.3.2 Interactive Meaning. In interactive, the participant wants to build a relationship with the audience or want to link with the audience.

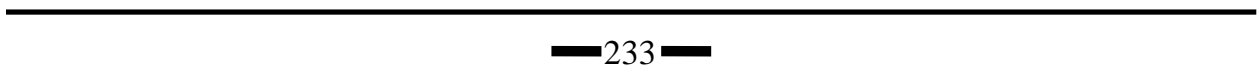




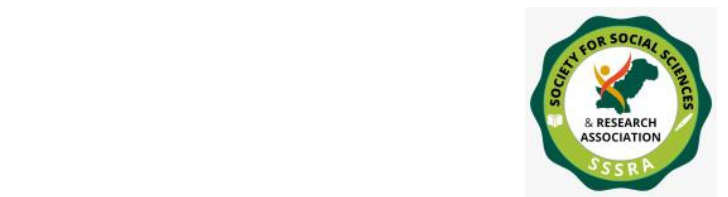

The Power of Political Subliminal ...

The interactive importance of pictures has three measurements: image act, social distance, and point of view. If the character in the image looking directly at the audience then they are demanding if they are not looking directly to an audience then the image is offering. Distance and their shots close-up, medium, or long create a relationship between the audience and Characters. The last element is perspective or point of view.

3.3.3 Compositional Meaning. Meaning is constructed by three interrelated frameworks: information value, salience, and framing. These frameworks are not confined to single pictures, yet they apply additionally to composite visuals.

Information value is related to three primary visual regions: left and right; top and base; and Center and edge. On account of left and right, the synthesis is organized along the parallel axis. The left side is identified to given data more like the situation of the image, which is thought to be natural and acknowledged as a state of departure for the message by the watcher. As, the right side is reserved for new information, to something unknown, requiring special attention or Answer of situation. The information situated at the top is introduced as basic or ideal, representing a fantasy...

\section{DISCUSSION AND ANALYSIS}

\section{Visual Social Semiotics Theory}

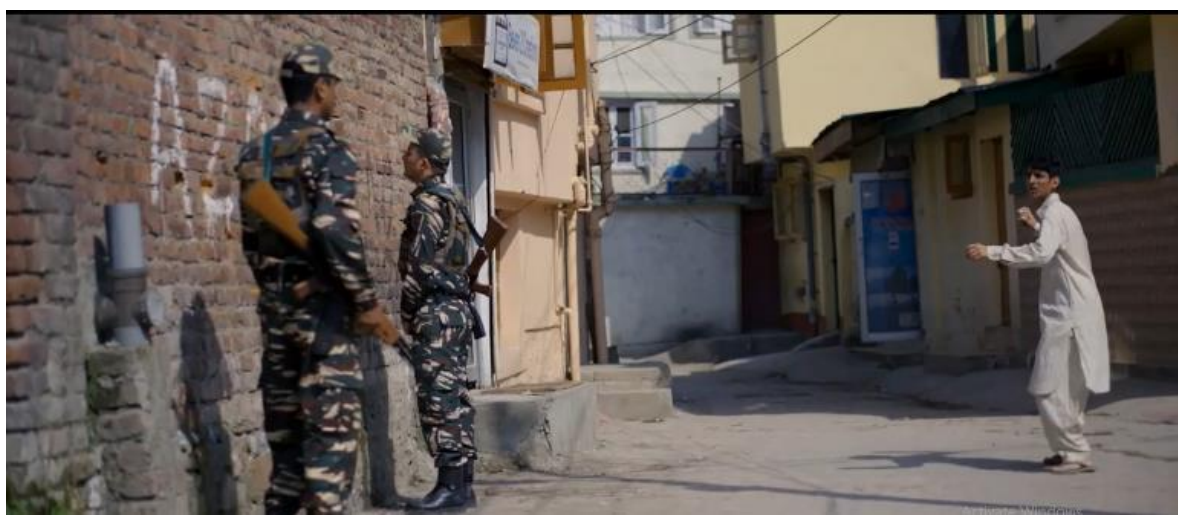

Figure 1. A boy throwing a stone at a soldier in the movie Hamid. 
The Power of Political Subliminal ...

Representational. This image has a narrative behind it. Vectors are very clear. Soldiers stunned expression towards the boy and the boy throwing a stone, it's a Tran's active action vector.

Interactive Meaning. There is no demand as the subject has no eye contact with viewers however there is offering gaze or present gaze which indicates the current scenario between soldier and a boy. The image is a Long shot, which means an impersonal relationship. The angle of both the person in the shot is vertical which indicating power.

Compositional Meaning. The image is giving Information, as both the subject lies left and right end, indicating a situation and answer and text behind the soldier on the wall indicating a message that current situation of Kashmir. The white color of the "Azadi" text and boy dress color is similar which indicating a depth of connection between them. The modality of the picture is highly naturalistic/realistic.

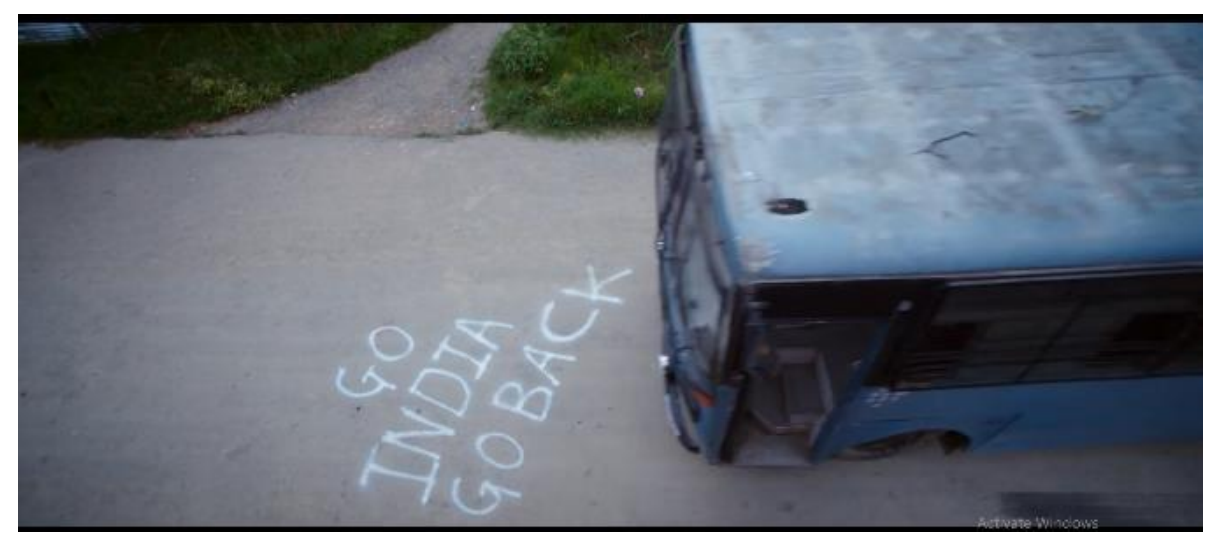

Figure 2. Text on Road

Representational. This image has a narrative behind it. It's a Tran's active action vector, as actions are visible bus crossing over the text on road.

Interactive Meaning. There is no demand however the image is offering a message. The image is a mid-shot, mean social relationship. Angle is horizontal.

Compositional Meaning. The image is clear Go back India" is at the center focus of the image and the military bus is on the right side New (answering) side is a message 
The Power of Political Subliminal ...

to protestors and viewers. The white color of "Go India Go Back" text and white color stand out from the picture and there is a connection in the image. The modality of the picture is highly naturalistic/realistic.

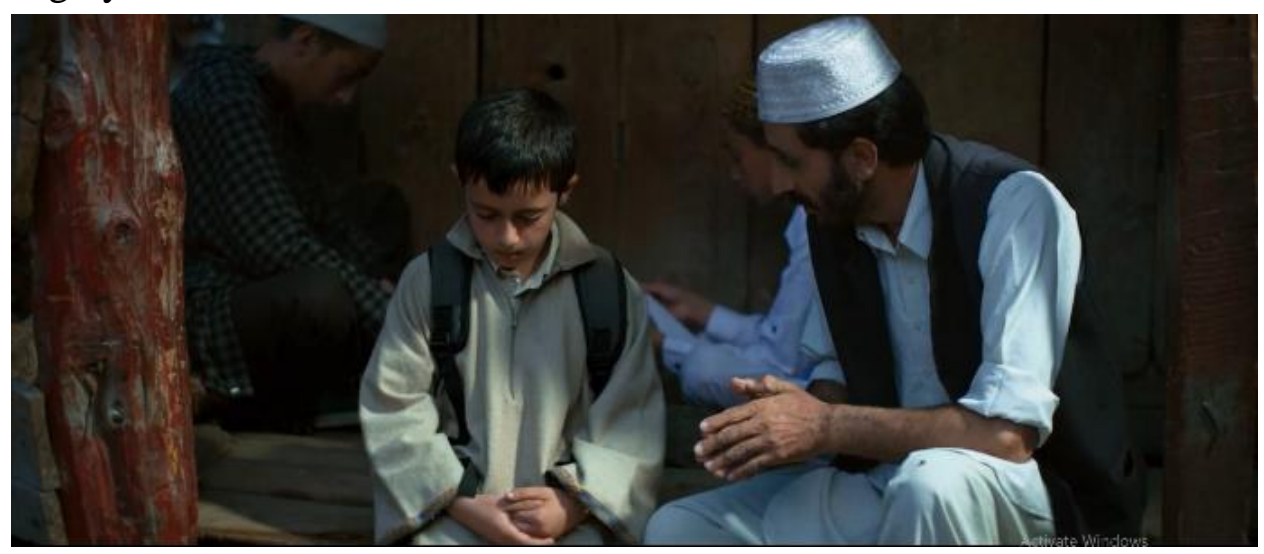

Figure 3. Man Manipulating Hamid

Representational. This image has a narrative behind it. It's a Tran's active action vector, as actions are visible man talking to a kid gently.

Interactive Meaning. There is no demand however the image is offering to the viewers a message. The image is a mid-shot, mean social relationship. Angle is horizontal.

Composition meaning. There are two subjects the first subject is a kid at the center and on the right side (New) the second is a Man. The subjects are connected as something the right side subject in explaining something to the center (main focused point) indicating something a man wants from kid to understand. Man dress is stand out due to its vibrant color from overall the picture and High realistic Modality is seen in this image. 


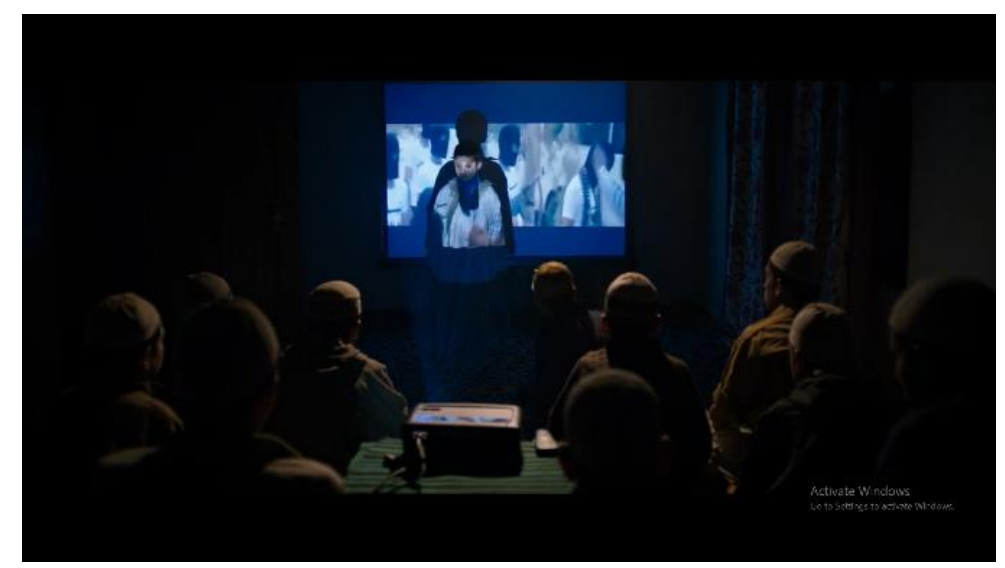

Figure 4. Children are trained as Militants

Representational. This image has a narrative behind it. It's a Tran's active action vector, as actions are played behind the boy on the screen which indicates the entire message.

Interactive Meaning. Contact of eyes of a boy is not to viewers but the boys sitting in front of him want audience attention to the message. The image is a long shot, a meaningful social relationship. Angle is horizontal.

Compositional. The image is centralized the main focus of the image to grab the attention of an audience, below is kids watching TV is reality given and New. The subject in the center is standout due to vibrancies the rest is dark show the aggression mystery. The background is more prominent in the image and focuses on viewers indicating a message to the audience. The image show reality of modality. 


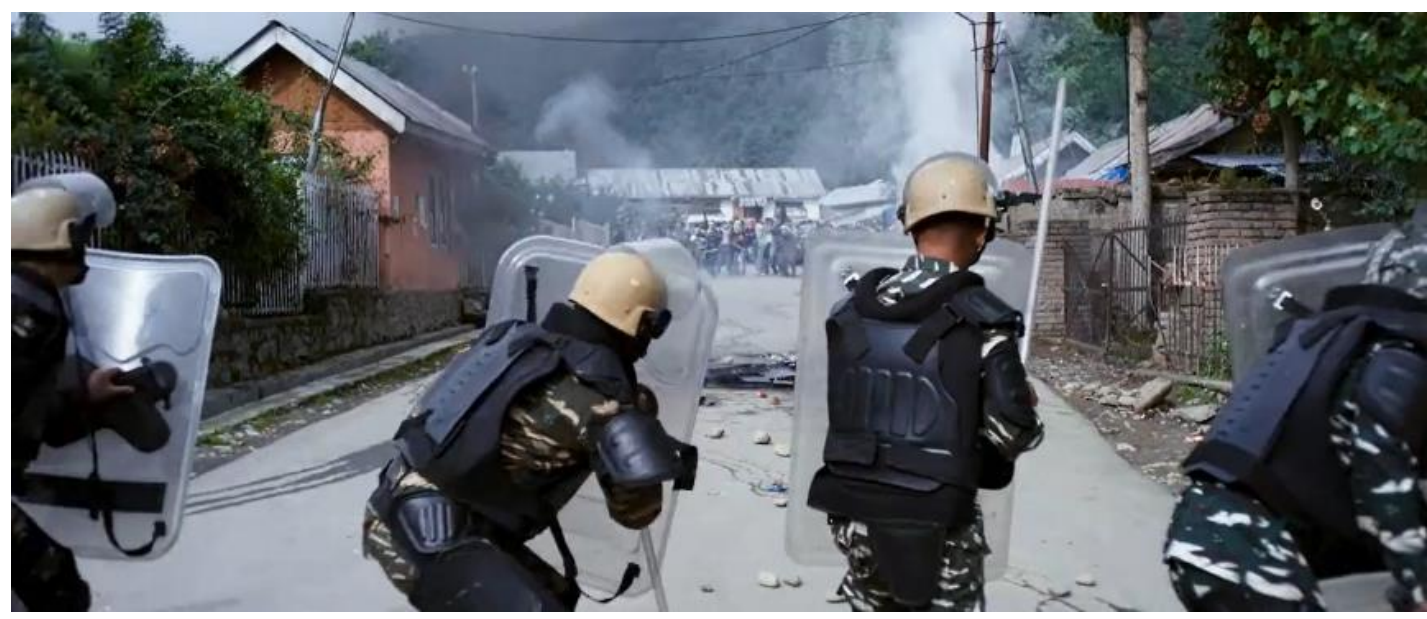

Figure 5. Protestors throwing stones at Soldiers

Representational. This image has a narrative behind it. It's a Tran's active action vector, as actions are played among the protestors of throwing a stone on soldiers and soldiers are shielding from them showing soldiers on good light and protestors on poor light.

Interactive Meaning. No demand contact again offering scenario to viewers. The image is mid-shot, which means Impersonal relationship. Angle is horizontal showing detachment to viewers.

Compositional. The image is centralized the main focus to grab the attention of the audience which depicting a scene of army soldiers and protestors. This scene shows two sides soldier a positive image and protestors a negative image. Soldier's standout in the picture as salient. The visuals are disconnect s there are so many colors and objects. It also has a high naturalistic modality due to its representation of reality in Kashmir. 
The Power of Political Subliminal ...

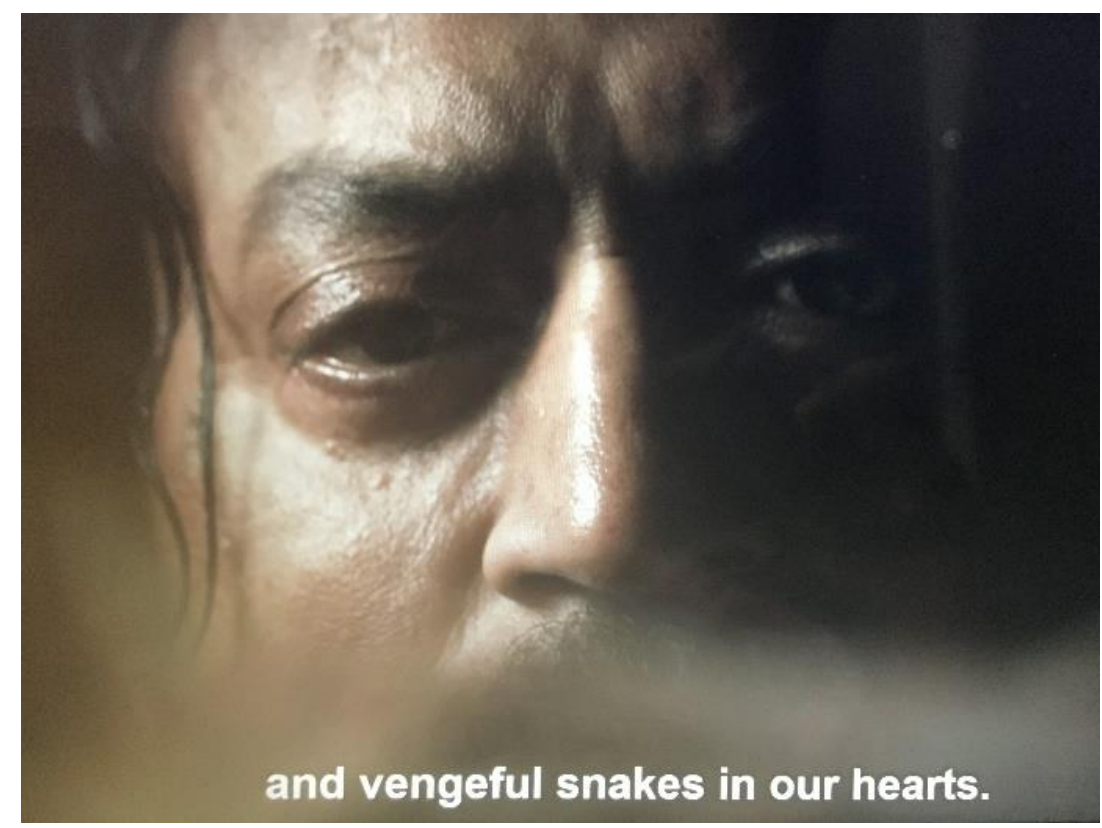

Figure 6. Roodhar (Played by Irrfan khan) in Haider movie

Representational. This image has a narrative behind it. It's non-trans active as there is no action in it because eyes are focused on something which is out of frame.

Interactive Meaning. No demand contact again offering or presenting a message to viewers. The image is a close-up shot means an Intimate relationship with the audience.

Compositional. The picture has a high realistic modality of a man close up suggesting a powerful message to the viewers. The contrast of low-value background and high-value expression act as frame grab the attention of viewers to the expression which depicts revenge aim. His all facial expression is centralized which is the core of the image.

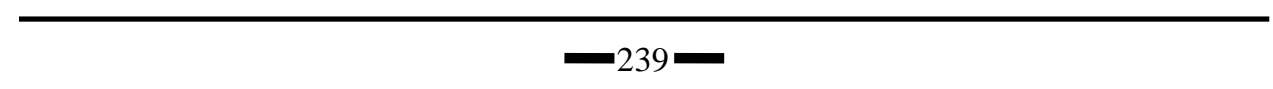




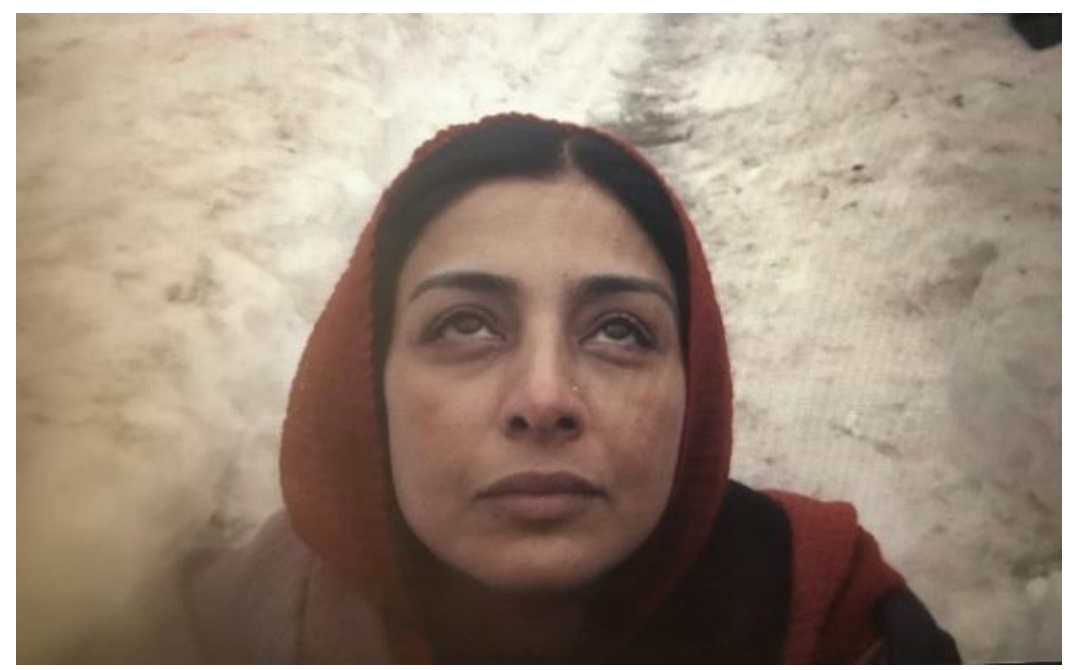

Figure 7. Ghazala killed herself and give the message of freedom

Representational. This image has a narrative behind it. It's non-trans active as there is no action in it because eyes are focused on something which is out of frame.

Interactive Meaning. No demand contact again offering or presenting a message to viewers. The image is a close-up shot means an Intimate relationship with the audience.

Compositional. The picture is a highly realistic modality of a woman whose eyes are up suggesting a powerful message to the viewers. The contrast of low-value background and high-value expression act as frame grab the attention of viewers to the expression which depicts freedom. Her all facial expression especially her eyes is centralized which is the core of the image. 


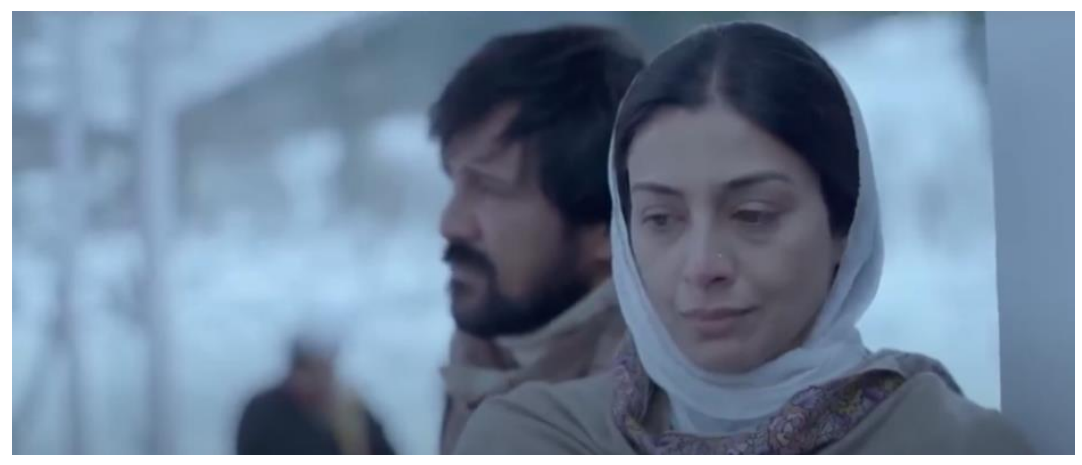

Figure 8. Ghazala indirectly called khurum traitor

Representational. This image has a narrative behind it. It's a Tran's active action vector, as actions are visible Ghazala talking kkhurum behind her. Vectors are shown through Ghazala gaze to her smile at Khhurum

Interactive Meaning. No demand contact again offering or presenting a subliminal message to viewers "he's becoming bloodthirsty wolf" by Khhurum indicating the action of IKHWAN-ul-Mukhbireen who are killing Kashmiri on which Gazala replied, "At least he is not cold-blooded snake" referring to Kashmiri who is working with other. The image is a close-up shot means an Intimate relationship with the audience.

Compositional. The placement of the character is on the right side "given" but the message she gave can be depicted through her gaze which is on the right side "Given" some information which is referring to khuhurum through Gaze. The contrast of lowvalue background and high-value expression act as frame grab the attention of viewers to the expression and Dialogues which depict Sarcasm. Her all facial expression especially eyes which are from right to left which is the core of the image. 


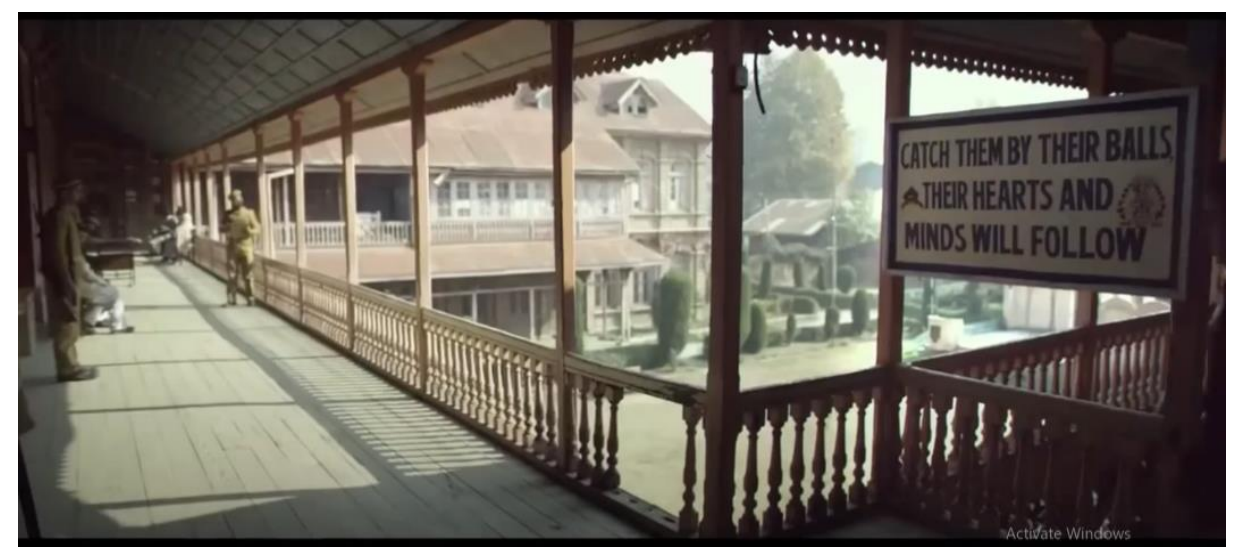

Figure 9. Theodore Roosevelt Phrase

Representational. This image has a narrative behind it. It's a non- Tran's active action vector, as there is no action in it just a message. The statement was likewise present in the 1976 film All the President's Men. By this, the film clarifies the philosophy of the Indian Army towards Kashmiri individuals.

Interactive Meaning. There is no demand however the image is offering a message. The image is a long shot, a meaningful social relationship. Angle is horizontal.

Compositional Meaning. The image on is the right side focuses on new information, to somewhat unidentified or offering special attention. The text stands out from the picture and there is a connection in the image. The modality of the picture is low naturalistic/realistic.

\section{CONCLUSION}

This Research Showed that subliminal messages do exist in Film. The film is a medium of mass media that has a significant influence in creating opinion. The film builds real causes/issues and interprets political thoughts into visuals. Indian films have a huge market overseas. This research discovered how films placed political views and Concepts through subliminal messages and manipulate them in such a way that audience the ordinary people are even being aware of how they are misguided. Bollywood has 


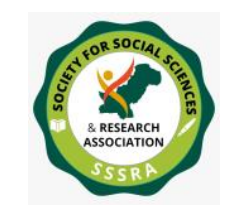

The Power of Political Subliminal ...

become an international communication medium and its depiction is valued in overseas markets.

Literature Review shed a come light to the political subliminal messages projection and its manipulation in media. It will provoke the audiences to think about the usage of such new mysterious method that treacherously implants a conflict of minds and hearts. The movies mostly concentrated on Kashmir, Terrorism and prisoner issue. The film makers make movies to cash public sentiment on box office. Films like -URI, Gadar, Loc Kargill and Border were prepared it for such movement. Hamid Haider are two movies which indirectly manipulated the viewer's perception through subliminal messages and targeting freedom movement in Kashmir and defended Indian army violation and brutality

Based on the theoretical framework of multimodal discourse analysis, the Research prepared a multimodal discourse analysis of the movie Hamid and Haider from the perspective of narrative and image meaning. To carry out this analysis with the association visual Social Semiotic Theory by Jewitt and Oyama will be applied for visual research of subliminal messages. Results show that there are political subliminal messages which are targeting and manipulating the audience to show a different perspective of the freedom movement and Indian brutality or violence.

Hamid and Haider reveal the pith of the speculation which expresses that Indian media and Government incorporate political subliminal messages which project a hidden boost and targeting freedom movement. The purpose of this study is to procure movie analysis as a way to critique the devastating situation and anti-humanist activities in Kashmir. Gaining awareness regarding the shortcomings of Muslims in Kashmir is an absolute necessity (Khalidi, 2019).

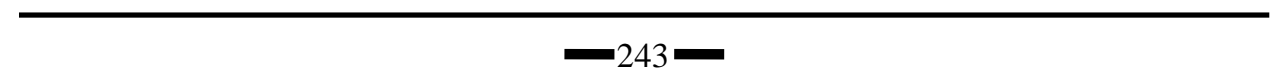


The Power of Political Subliminal ...

\section{REFERENCES}

Amin, M. M. (2017). Reconsidering Kashmiri Muslim Identity: A contextualization of Muslims of Kashmir within the broader 'political ecology'of South Asia. In [2017] Congreso Internacional de Ciencias Sociales.

Amre, H. (2017). Hollywood \& the Prefiguring of 911. docx.

Anzai, Y. (2003). The perception of Japanese university students concerning product placement in Hollywood movies. The Economic Journal of Takasaki City University of Economics, 46(3), 107-116.

Atrees, F. F. (2015). The concept of subliminal messages in Brand design. International Design Journal, 5(1), 23-28.

Banga, B. \&. (n.d.). Representation of Political Ideology through Bollywood Movies: A Critical Study of the Movie "Uri-The Surgical Strike".

Birgit Meyer, A. M. (2005). Religion, Media, and the Public Sphere. Indiana University Press..

Cartelli, T. (2019). States of Exception: Remembering Shakespeare Differently in Anatomie Titus, Forget Hamlet \& Haider. In Reenacting Shakespeare in the Shakespeare Aftermath. Palgrave Macmillan, New York., (pp. 119-151).

Çelikiz, E. (n.d.). Secret Ideological-Political Messages of Hollywood Movies: Flags of Our Fathers and Examples of Honor and Courage Films. Интеркултурна комуникаџия, медии, изкуства Intercultural Communication, Media, Arts. 
Chasanah, N. (2020). Revealing the Hidden Message from Cigarette Advertisement: Multimodal Discourse Analysis. LITERA KULTURA, 8(2).

Chen, Y. \&. (2015). Interpretation of the representational meaning of movie posters from the perspective of multimodal discourse analysis. In International Conference on Education, Language, Art and Intercultural Communication (ICELAIC-14). Atlantis Press.

Cole, J. (2018). he Hidden Power of Superheroes: The Ability of Superhero Movies to Influence Political Attitudes.

Deba, R. S. (2016). Unveiling the subliminal messages opposing islam homeland tv series.

Deba, R. S., \& Boudjelit, A. (2016). Unveiling the subliminal messages opposing islam homeland tv series.

Dijksterhuis, Aarts, \& Smith. (2005). The Power of the Subliminal: On Subliminal Persuasion and Other Potential Applications. The new unconscious, , 1, 77-106.

FICCI/KPMG. (2013). The power of a billion Realizing the Indian dream. FICCI-KPMG Indian Media and Entertainment Industry Report 2013.

Florea, M. (2016). HISTORY OF THE 25TH FRAME. THE SUBLIMINAL MESSAGE. International Journal of Communication Research, 6(3), 261.

Jessop, B. ( 2008). shaping Public Opinion and the White Coated Propagandists. Reshaping the International Order. 
The Power of Political Subliminal ...

Khan, M. A. (2011). Portrayal of Muslims in Indian Cinema: A Content Analysis of Movies during. Pakistan Journal of Islamic Research, 8, 1-15.

Khan, M., \& Bokhari, S. (2011). Portrayal of Muslims in Indian Cinema. Pakistan Journal opf Islamic Research, Vol 28.

Kirdar, Y. (2012). Mysticism in subliminal advertising. JAMMO ISSN 2146-3328, 4(15), 222-239.

Klimov, B. (2003). There! Did you see it?; Care! They do see you. . . Subliminal messages in advertisement, movie making and cartoons in a 'not so-innocent world'. Profit driven or 'dark' conspiracy? Munich Personal RePEc Archive.

Maisuwong, W. (2012). The Promotion of American Culture through Hollywood movies to the world. International Journal of Engineering Research \& Technology (IJERT), ISSN: 2278-0181 Vol. 1 Issue 4.

Malika Singh, R. N. (2015). Psychology of Brand Creation and Management: Subliminal Advertising. International Journal of Science and Research (IJSR), 849.

Marchman, R. (2016). A new hue for heroism-or-A multi-method evolutionary analysis of the Green Lantern comic book series for insights on the changing cultural perspective of heroism. San José State University.

McAdams, J. (2015). Portrayals and Presence of Adult Female Characters in Children's Picture Books: A Content Analysis of Bestsellers from the Past Five Years. UNC Carolina Digital Repository. 
Mehidyeva, M. (2016). Visual analysis of political campaign posters in US 2016 presidential elections . (Doctoral dissertation, Bachelor's thesis, State University of New York).

Mookherjee, T. (. (2016). Absence and repetition in Vishal Bhardwaj's Haider. . Cogent Arts \& Humanities, 3(1), 1260824.

Murty, M. (2009). Representing Hindutva: Nation, Religion and Masculinity in Indian Popular Cinema, 1990 to 200. Popular Communication: The International Journal of Media and Culture.

nye, j. (2008). Public diplomacy and soft power. he annals of the American academy of political and social science, 616(1), 94-109.

Ostman, R. E. (1996). Disney and its conservative critics: Images versus realities. Journal of Popular Film and Television, 24(2), 82-89.

Ramadan, T. (2010). The Quest for Meaning: Developing a Philosophy of Pluralism. Penguin UK, 141.

Ramadan, T. (2010). The Quest for Meaning: Developing a Philosophy of Pluralism. Penguin

Silverman, L. M. (1978). Effect of subliminal stimulation of symbiotic fantasies on behavior modification treatment of obesity. Journal of Consulting and Clinical Psychology.

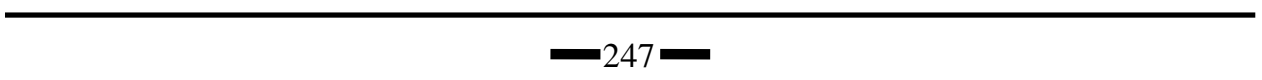


Spencer, D. M. (2019). Azadi activists abroad: transnational activism in the New Kashmiri Freedom Movement.

Takahashi, K. (2008). Effect of Subliminal Messages and Suggestions on Memory: Isolating the Placebo Effect.

Thoraval, Y. (2008). The Cinema of India. India: Indian Macmillan.

Thussu, D. K. (2006). Media on the move: Global flow and contra-flow. Routledge.

Turow, J. (2011). Media Today: An Introduction to Mass Communication. Taylor \& Francis.

Vokey, J. R. (1985). Subliminal messages: Between the devil and the media. American Psychologist, 40(11), 1231.

Yalcin, K. (2012). Mysticism in Subliminal Advertising. JAMMO ISSN 2146-3328,, 4, 18. 